\title{
Dyspnea catastrophizing and neural activations during the anticipation and perception of dyspnea
}

\author{
M. Cornelia Stoeckel ${ }^{1} \quad$ Roland W. Esser ${ }^{1} \quad$ Matthias Gamer ${ }^{1,2}$ | \\ Christian Büchel $^{1}$ | Andreas von Leupoldt ${ }^{1,3}$
}

${ }^{1}$ Department of Systems Neuroscience, University Medical Center HamburgEppendorf, Hamburg, Germany

${ }^{2}$ Department of Psychology 1, University of Würzburg, Würzburg, Germany

${ }^{3}$ Health Psychology, University of Leuven, Leuven, Belgium

\section{Correspondence}

Andreas von Leupoldt, $\mathrm{PhD}$, Health

Psychology, University of Leuven,

Tiensestraat 102, B-3000 Leuven,

Belgium.

Email: andreas.vonleupoldt@kuleuven.be

\section{Funding information}

German Research Foundation (DFG LE 1843/9-2, 10-1, 10-3), Research Fund KU Leuven, Belgium (STRT/13/002), Herculesstichting, Belgium (AKUL/13/07), Flemish Government, Belgium, Methusalem grant "Asthenes" (METH/15/011) (to A. v. L.)

\begin{abstract}
Dyspnea is an aversive symptom in various diseases. High levels of negative affectivity are typically associated with increased dyspnea and changes in its neural processing. Recently, more dyspnea-specific forms of negative affectivity such as dyspnea catastrophizing were suggested to contribute to increased perception of dyspnea beyond effects of rather unspecific negative affectivity such as general anxiety levels. The involved neural mechanisms have not yet been explored. Therefore, the present retrospective analysis examined the associations of dyspnea catastrophizing with neural activations during the anticipation and perception of dyspnea. Sixty-six healthy volunteers underwent 20 blocks of inspiratory resistive load breathing with parallel acquisition of fMRI data. Loads inducing either severe or mild dyspnea (dyspnea conditions) were presented in alternating order, with each condition being visually cued (anticipation conditions). Dyspnea catastrophizing and general trait anxiety were measured with the Breathlessness Catastrophizing Scale (BCS) and the State-Trait Anxiety Inventory, respectively. Correlating the BCS scores with neural activations during the perception of dyspnea yielded no significant results. However, during the anticipation of dyspnea, BCS scores correlated positively with activations of the anterior cingulate cortex (ACC), even after controlling for general anxiety levels. These activations in the ACC were not related to concurrent respiratory parameters. Results suggest that dyspnea catastrophizing in healthy volunteers is associated with stronger ACC recruitment during dyspnea anticipation. Given the established role of the ACC in processing affective states, affect regulation, and antinociception, this might reflect increased affective and/or top-down modulatory processing in individuals with higher dyspnea catastrophizing when anticipating dyspnea.
\end{abstract}

\section{KEY W O R D S}

affect, anxiety, fMRI, middle-age adults, respiration, sensation/perception

\section{1 | INTRODUCTION}

Dyspnea (breathlessness) is an aversive symptom in numerous prevalent diseases including respiratory, cardiac, cancerogenic, neuromuscular, and psychiatric conditions (American Thoracic Society, 1999). Dyspnea is a highly frightening experience for many patients and an important predictor of exercise intolerance, reduced quality of life, and even mortality (Parshall et al., 2012). It is estimated that up to $25 \%$ of the general population and up to $50 \%$ of severely ill patients are suffering from dyspnea, which constitutes a substantial individual as well as social and economic burden (Laviolette, Laveneziana, \& ERS Research Seminar Faculty, 2014; Mahler \& O’Donnell, 2015).

Recent research has demonstrated that not only physiological mechanisms, but also psychological factors contribute significantly to the subjective perception of dyspnea, among which negative affective states and personality traits such as 
anxiety seem the most frequently examined factors (Hayen, Herigstad, \& Pattinson, 2013; Janssens, Verleden, De Peuter, Van Diest, \& Van den Bergh, 2009; Laviolette et al., 2014; Scano, Gigliotti, Stendardi, \& Gagliardi, 2013; von Leupoldt, van den Bergh, \& Davenport, 2014). For example, it has been shown that highly anxious patients with asthma or chronic obstructive pulmonary disease (COPD) report more dyspnea than less anxious patients in everyday-life situations (Janson, Björnsson, Hetta, \& Boman, 1994; Xu et al., 2008). Also, during the experimental induction of dyspnea, more anxious patients with asthma or COPD as well as healthy individuals perceive greater dyspnea than their less anxious counterparts independent of respiratory changes (Alius, Pané-Farré, Von Leupoldt, \& Hamm, 2013; Livermore et al., 2008; Spinhoven, van Peski-Oosterbaan, Van der Does, Willems, \& Sterk, 1997; von Leupoldt, Taube, Lehmann, Fritzsche, \& Magnussen, 2011).

Previous neuroimaging studies demonstrated that negative affectivity might also impact the neural processing of respiratory sensations (Chan et al., 2015; Chan, von Leupoldt, Bradley, Lang, \& Davenport, 2012; Chan, von Leupoldt, Liu, \& Hsu, 2014; Chenivesse et al., 2014; von Leupoldt, Chan, Esser, \& Davenport, 2013). It has been suggested that this impact is mediated by (para)limbic brain areas such as insular cortex, anterior cingulate cortex (ACC), and amygdala (Davenport \& Vovk, 2009; Evans, 2010; Herigstad, Hayen, Wiech, \& Pattinson, 2011; Paulus, 2013; Scano et al., 2013; von Leupoldt et al., 2008; von Leupoldt $\&$ Dahme, 2005). These areas are not only involved in the processing of dyspnea and other aversive bodily sensations such as pain (Craig, 2002; Tracey \& Mantyh, 2007; Van Oudenhove \& Aziz, 2013; von Leupoldt et al., 2009), but are also key areas in the processing of negative affectivity such as anxiety (Adolphs, 2013; Etkin, Egner, \& Kalisch, 2011; Etkin \& Wager, 2007; Sehlmeyer et al., 2009). Notably, activations in these areas are not restricted to the perception of aversive stimuli, but are already present during their anticipation including the expectation of upcoming dyspnea (Faull, Jenkinson, Ezra, \& Pattinson, 2016; Grupe \& Nitschke, 2013; Holtz, Pané-Farré, Wendt, Lotze, \& Hamm, 2012; Paulus et al., 2012; Stoeckel, Esser, Gamer, Kalisch et al., 2015; Stoeckel, Esser, Gamer, Büchel, \& von Leupoldt, 2016).

However, most previous studies examined the impact of rather unspecific forms of negative affectivity (e.g., general anxiety levels) on the anticipation and perception of dyspnea. Only recently, studies began to focus on more dyspneaspecific forms of negative affectivity including breathlessness beliefs, fear of suffocation/dyspnea, and dyspnea catastrophizing (Alius et al., 2013; Fischer et al., 2012; Janssens et al., 2011; Keil et al., 2014; Kühl, Kuhn, Kenn, \& Rief, 2011; Pappens, Smets, Van Den Bergh, \& Van Diest, 2012;
Sutton, Cooper, Pimm, \& Wallace, 1999). These dyspneaspecific forms of negative affectivity have been shown to contribute to several clinical outcomes even after controlling for unspecific general anxiety levels and presumably provide a more specific target for individualized therapeutic interventions (Hayen et al., 2013; von Leupoldt \& Janssens, 2016). For example, it has been demonstrated that dyspnea catastrophizing (i.e., an exaggerated negative orientation toward noxious stimuli characterized by rumination, magnification of their threat value, and perceived inability to control) is related to higher dyspnea, psychological distress, and performance in the stair test after rehabilitation (Livermore et al., 2015; Livermore, Sharpe, \& McKenzie, 2012; Solomon et al., 2015; Sutton et al., 1999).

The approach of dyspnea-specific forms of negative affectivity has been adapted from other symptom domains, especially chronic pain, where concepts of pain-specific fear and pain catastrophizing were successfully established years ago (Leeuw et al., 2007; Sullivan et al., 2001). For example, several studies demonstrated that pain catastrophizing is more strongly correlated with disability than the pain itself (Holroyd, Drew, Cottrell, Romanek, \& Heh, 2007; Severeijns, Vlaeyen, van den Hout, \& Weber, 2001; Sullivan et al., 2001; Sullivan, Lynch, \& Clark, 2005). Previous neuroimaging studies showed that pain catastrophizing is associated with brain activation during the perception of pain, which included affect-related brain areas such as the insular and ACC (Cottam, Condon, Alshuft, Reckziegel, \& Auer, 2016; Gracely et al., 2004; Mathur et al., 2016; Seminowicz \& Davis, 2006). However, the neural mechanisms associated with dyspnea catastrophizing during the anticipation and perception of dyspnea have not been examined yet.

Therefore, the present study retrospectively analyzed data from healthy individuals from two previous fMRI studies for which questionnaire data on individual levels of dyspnea catastrophizing as well as on general trait anxiety were available (Esser et al., 2017; Stoeckel, Esser, Gamer, Büchel, \& von Leupoldt, 2015; Stoeckel et al., 2016). These were correlated with brain activations during the anticipation and perception of resistive load-induced dyspnea. Specifically, we tested the hypothesis that dyspnea catastrophizing would be associated with activations in (para)limbic brain areas such as insula, ACC, and amygdala.

\section{MATERIALS AND METHOD}

\section{1 | Participants}

We pooled data from two previous studies (Subsample 1: Esser et al., 2017; Subsample 2: Stoeckel, Esser, Gamer, Büchel, Kalisch et al., 2015; Stoeckel et al., 2016) to obtain a sample of 66 healthy participants without history of 
TABLE 1 Baseline mean $(S D)$ characteristics of participants

\begin{tabular}{|c|c|c|c|}
\hline Characteristics & $\begin{array}{l}\text { Whole sample } \\
(N=66)\end{array}$ & $\begin{array}{l}\text { Subsample } 1 \\
(N=21)\end{array}$ & $\begin{array}{l}\text { Subsample } 2 \\
(N=45)\end{array}$ \\
\hline Age (years) & $39.6(17.8)$ & $63.4(8.8)$ & $28.5(6.1)$ \\
\hline Sex (female/male) & $29 / 37$ & $11 / 10$ & $18 / 27$ \\
\hline Smoker/nonsmoker & $15 / 51$ & $2 / 19$ & $13 / 32$ \\
\hline Height $(\mathrm{cm})$ & $177.0(9.7)$ & $173.4(9.4)$ & $178.7(9.5)$ \\
\hline Body mass index $\left(\mathrm{kg} / \mathrm{m}^{2}\right)$ & $24.1(2.9)$ & $25.7(3.3)$ & $23.4(2.4)$ \\
\hline $\mathrm{FEV}_{1}(\mathrm{~L})$ & $4.4(1.1)$ & $3.6(0.9)$ & $4.8(1.0)$ \\
\hline FVC (\% predicted) & $119.9(13.8)$ & $126.2(13.0)$ & $117.0(13.3)$ \\
\hline Dyspnea catastrophizing (BCS) & $7.8(8.6)$ & $1.4(3.1)$ & $10.7(8.8)$ \\
\hline Trait Anxiety (STAI-T) & $33.1(6.8)$ & $31.1(5.7)$ & $34.1(7.1)$ \\
\hline
\end{tabular}

Note. $\mathrm{FEV}_{1}=$ forced expiratory volume in $1 \mathrm{~s} ; \mathrm{FVC}=$ forced vital capacity; $\mathrm{BCS}=$ Breathlessness Catastrophizing Scale; STAI-T = State-Trait Anxiety InventoryTrait.

respiratory disease (Table 1). This approach allowed adequate statistical power (Desmond \& Glover, 2002) and the mapping of a wider range of age and dyspnea catastrophizing levels. Participants were recruited from a local database. Inclusion criteria were an age between 20 and 80 years and fluency in German language. Exclusion criteria were impaired lung function, airway symptoms (e.g., cold, cough) within 2 weeks prior to testing, history of respiratory, cardiovascular, psychiatric, or neurological disease, pregnancy, and conditions preventing MRI scanning (e.g., metallic implants). Normal lung function (forced expiratory volume in $1 \mathrm{~s}$ in percent predicted $>80 \%$ ) was confirmed by standard spirometry prior to testing (Miller et al., 2005). All participants provided written informed consent prior to the study. The study protocol was approved by the Ethics Committee of the Medical Association Hamburg (PV3662).

\subsection{Anxiety measures}

Prior to scanning, dyspnea catastrophizing was assessed with the Breathlessness Catastrophizing Scale (BCS; Solomon et al., 2015), a recently adapted version of the widely used Pain Catastrophizing Scale (Sullivan, Bishop, \& Pivik, 1995). The BCS is a 13-item scale asking respondents to rate "the degree to which you have these thoughts and feelings when you are experiencing breathlessness" (e.g., "I keep thinking about how severe the breathlessness is"; "It's terrible and I think it's never going to get any better"). Items are rated on a 5-point scale (range: $0=$ not at all, $4=$ all the time), which are condensed into a sum score (range: 0-52) with higher scores indicating greater anxiety. The BCS was recently validated in a sample of COPD patients and showed adequate construct validity and internal consistency (Cronbach's alpha $=.96$; Solomon et al., 2015).

Levels of general anxiety were measured with the trait version of the validated State-Trait Anxiety Inventory (STAI-T; Spielberger, Gorsuch, \& Lushene, 1970). The STAI-T is a 20-item scale asking respondents "to indicate how you generally feel" (e.g., "I worry too much over something that really doesn't matter"; "I get in a state of tension or turmoil as I think over my recent concerns and interests"). Items are rated on a 4-point scale (range: $1=$ almost never, $4=$ almost always), which are condensed into a sum score (range: 20-80) with higher scores indicating greater anxiety.

\section{3 | Apparatus and respiratory measurements}

In order to induce dyspnea, we used a tightly fitting face mask (series 7400, Hans Rudolph Inc., Shawnee, KS) that was connected with an MRI-compatible pneumotachograph (Flowsensor type II for ZAN 600 unit, ZAN Messgeräte $\mathrm{GmbH}$, Oberhulba, Germany), followed by a two-way nonrebreathing valve (series 2630, Hans Rudolph Inc.). Separate ports recorded end-tidal $\mathrm{CO}_{2}$ pressure $\left(\mathrm{PET}_{\mathrm{CO}_{2}}\right)$ and peak inspiratory mouth pressure $\left(\mathrm{P}_{\mathrm{I}}\right)$. The inspiratory arm of the 
two-way nonrebreathing valve was connected to a $2.6-\mathrm{m}$ tube for the easy introduction and removal of MRcompatible resistive loads. The expiratory arm was left open and prevented rebreathing of $\mathrm{CO}_{2}$. The breathing circuit allowed the continuous measurement of respiratory parameters including $\mathrm{PET}_{\mathrm{CO} 2}$, peak inspiratory pressure, tidal volume $\left(\mathrm{V}_{\mathrm{T}}\right)$, breathing frequency (f), minute ventilation $\left(\mathrm{V}_{\mathrm{E}}\right)$, and inspiratory time $\left(\mathrm{T}_{\mathrm{I}}\right)$.

\subsection{Induction and measurement of perceived dyspnea}

Dyspnea was explained to our participants as a sensation of difficult and uncomfortable breathing. In a pretest, participants were familiarized with the setup and the sensation of loaded breathing. The pretest also served for the selection of loads suitable to induce a sensation of severe dyspnea in each individual participant. Participants were placed in a supine position and presented with inspiratory resistive loads of increasing magnitude. Each load was presented for $24 \mathrm{~s}$. Following each load, participants rated the intensity of dyspnea induced on a visually presented Borg scale $(0=n o t$ noticeable to $10=$ maximally imaginable; Borg, 1982). Blocks of loaded breathing alternated with blocks of unloaded breathing, and load magnitudes were increased until participants reliably reported a sensation of "severe" dyspnea (Borg score $\geq 5$ ). The respective load was then used to induce severe dyspnea during the scanning protocol (mean load resistance $=2.6 \mathrm{kPa} / \mathrm{l} / \mathrm{s}, S D=1.40$ ). For the baseline condition of "mild" dyspnea, the smallest resistive load that was reliably rated as different from unloaded breathing was used (mean load resistance $=0.26 \mathrm{kPa} / \mathrm{l} / \mathrm{s}, S D=0.17$ ).

\section{5 | Instructions}

Prior to scanning, participants were guided through the experimental protocol including explanations on the visual cues for each experimental condition and the use of Borg scales for ratings of dyspnea intensity and unpleasantness. During this computer-based instruction, participants were asked to memorize the association of colored cues and experimental conditions and pointed to the fact that dyspnea intensity and unpleasantness were assessed in randomized order. During a short test run in the scanner, participants were reminded of the cue-condition association and acquainted with the button response system.

\section{6 | Experimental protocol}

After standardized instruction, subjects entered the fMRI scanner with the face mask tightly fitted. We used Presentation software (Neurobehavioral Systems, Inc., Albany, CA) to project visual cues and Borg scales into the scanner bore via a mirror system and to send condition markers to the ZAN system. Subjects were presented with the color-coded cue in the shape of a cross for the anticipation period. After $6 \mathrm{~s}$, the cross changed from a thin line into a bold line, and the preselected load was manually introduced for $24 \mathrm{~s}$. There were 10 blocks of mild and 10 blocks of severe dyspnea presented in alternating order. Each load was followed by two Borg rating scales for the preceding block: one on dyspnea intensity and one on dyspnea unpleasantness. The order of the scales was randomized, and the ratings lasted approximately $20 \mathrm{~s}$. Immediately following the brain scan, subjects rated the perceived quality of dyspnea on a verbal descriptor list outside the scanner (von Leupoldt et al., 2007).

\section{7 | fMRI data acquisition}

A 3-Tesla TRIO-Magnetom scanner (Siemens, Medical Solutions, Erlangen, Germany) combined with a standard 32channel head coil was used for the acquisition of MRI data. Functional data were acquired in 48 continuous axial slices in descending order with $2 \times 2 \mathrm{~mm}$ in-plane resolution, 2mm slice thickness, and a 1-mm gap using T2*-weighted parallel echoplanar imaging $(\mathrm{TR}=2,870 \mathrm{~ms}, \mathrm{TE}=25 \mathrm{~ms}$, flip angle $=80^{\circ}$, field of view $=208 \times 208 \mathrm{~mm}$ ) with GRAPPA acceleration $(R=2)$. The first five volumes were discarded to allow for T1 saturation. A standard MP-RAGE sequence $(1 \times 1 \times 1 \mathrm{~mm}$ spatial resolution, $\mathrm{TR}=2,300 \mathrm{~ms}$, $\mathrm{TE}=2.98 \mathrm{~ms}$, flip angle $=9^{\circ}$, field of view $=256 \times 256$, 240 slices) was used to obtain a high-resolution T1-weighted structural brain scan.

\section{8 | Data analysis}

Means of intensity and unpleasantness ratings were compared between mild and severe dyspnea conditions using paired $t$ tests. Respiratory parameters were compared between mild and severe dyspnea conditions and between cue mild and cue severe anticipation conditions using paired $t$ tests (Bonferroni-corrected). These analyses were calculated with SPSS 20.0 software (SPSS Inc., Chicago, IL) using a significance level of $p<.05$.

Data preprocessing and statistical analysis were carried out using SPM8 (www.fil.ion.ucl.ac.uk/spm) and FSLMELODIC 3.0 (Beckmann \& Smith, 2004). We used the DARTEL protocol implemented within SPM8 to create a custom template within standard space based on the T1 images of all participants. Functional data were unwarped, realigned using six-parameter rigid-body transformations, and normalized to the custom-made T1 template using linear and nonlinear transformations. Afterward, and as previously suggested for fMRI studies using respiratory manipulations 
(Brooks, Faull, Pattinson, \& Jenkinson, 2013; Evans, 2010), physiological noise correction was performed. Noise was identified following a two-step probabilistic independent component analysis: Preprocessed data were first whitened and projected into a 40-dimensional subspace using a principal component analysis and further decomposed into sets of vectors that describe signal variation across the temporal domain (time courses) and across the spatial domain (spatial maps) by optimizing for non-Gaussian spatial source distributions using an independent component analysis (Beckmann \& Smith, 2004). Each component was then categorized as either function related (resting-state networks or paradigm related) or noise related (e.g., noise due to respiration, cardiac activity, motion, or scanner drifts) by considering the spatial pattern, the time course, and the power distribution following a heuristic described by Kelly et al. (2010). This procedure also controlled for potential effects of $\mathrm{PET}_{\mathrm{CO} 2}$ fluctuations on brain activation. The categorization of two independent raters showed high agreement (95.9\%, Cohen's kappa $=0.64)$. Components consistently identified as noise were filtered out. Filtered functional data were then smoothed using a $6 \times 6 \times 6 \mathrm{~mm}$ full-width at halfmaximum Gaussian filter.

For statistical analyses and following the preprocessing/ noise correction procedures, data were high-pass filtered with a 128-s cutoff, while serial correlations were accounted for by using an autoregressive model. Data modeling on the first level involved separate regressors for each condition (cue mild, mild dyspnea, cue severe, severe dyspnea, rating periods) based on the canonical hemodynamic response function implemented in SPM8. Mean BOLD signal intensity of each image was included as regressor of no interest. On the subject level, we contrasted cue severe versus cue mild and severe versus mild dyspnea to extract brain areas that show more activation during the anticipation and perception of severe versus mild dyspnea, respectively. These two contrast images per subject were then entered into separate random-effects correlation analyses with scores from BCS and STAI-T as covariates of interest.

For statistical inference, we used a two-step approach: first, we tested for significant correlations of dyspnea catastrophizing scores (BCS), after controlling for individual's general anxiety levels (STAI-T), throughout the entire brain with a whole-brain familywise error corrected $p<.05$. For the second analysis, we directly tested the hypothesis that, after controlling for individuals' general anxiety levels (STAI-T), dyspnea catastrophizing scores (BCS) would correlate with activation in the insula, ACC, and the amygdala as regions of interest (ROIs). Bilateral masks were generated from the automated anatomical labeling template described by Tzourio-Mazoyer et al. (2002). Activation within these regions was considered significant if exceeding a threshold of $p<.05$ after familywise error correction within the masks. Furthermore, we examined potential associations between significant brain activations (individual betas from peak voxels) and parallel respiratory parameters by offline partial correlation analyses (controlled for STAI-T). In addition, we tested the associations between significant brain activations (individual betas from peak voxels) and dyspnea catastrophizing scores (BCS), when controlling for potential effects of age by offline partial correlation analyses. In an explorative correlational analysis (Pearson's $r$ ), we tested for potential associations between dyspnea catastrophizing scores (BCS) and baseline characteristics as well as respiratory parameters during scanning.

\section{3 | RESULTS}

\section{1 | Respiratory parameters and dyspnea ratings}

Subjective dyspnea ratings confirmed successful induction of mild and severe resistive load-induced dyspnea, respectively. Ratings for intensity and unpleasantness of dyspnea were significantly higher during severe (mean $\pm S D=4.48 \pm 1.64$ and $3.68 \pm 1.87$, respectively) than during mild dyspnea (mean $\pm S D=0.75 \pm 0.63$ and $0.64 \pm 0.72$, respectively; $t$ $(65)=22.80$ and $t(65)=16.45, p s<.001)$. Resistive loadinduced dyspnea was mainly described as "increased work and effort of breathing" on the verbal descriptor list.

Respiratory parameters showed significant variation between dyspnea conditions (Table 2). While $\mathrm{f}$ and $\mathrm{V}_{\mathrm{E}}$ where significantly reduced during the perception of severe compared to mild dyspnea, $t(65)=-5.74$ and $t(65)=-4.73$, respectively; $p s<.001, \mathrm{P}_{\mathrm{I}}$ and $\mathrm{T}_{\mathrm{I}}$ were significantly increased, $t(65)=15.01$ and $t(65)=6.90$, respectively; $p s<.001$. For the anticipatory cue conditions, only $\mathrm{PET}_{\mathrm{CO} 2}$ was marginally, though significantly, lower during the cue severe compared to the cue mild, $t(65)=3.58, p=.012$.

\section{2 | Associations between dyspnea catastrophizing, baseline characteristics, and respiratory parameters}

No significant associations were observed between dyspnea catastrophizing scores (BCS) and baseline characteristics as well as respiratory parameters during scanning $(r s<.22$, $p s>.07)$, except for a significant correlation between BCS scores and age $(r=-.49, p<.001)$.

\section{3 | Functional imaging data}

For the perception of dyspnea (contrast: severe vs. mild dyspnea), neither the whole-brain analysis nor the ROI-based 
TABLE 2 Group mean $(S D)$ respiratory parameters for conditions of anticipation and perception of dyspnea

\begin{tabular}{|c|c|c|c|c|}
\hline & \multicolumn{2}{|c|}{ Anticipation of dyspnea } & \multicolumn{2}{|c|}{ Perception of dyspnea } \\
\hline $\mathrm{PET}_{\mathrm{CO} 2}(\mathrm{mmHg})$ & $32.84(3.46)$ & $32.46(4.06)^{*}$ & $32.72(4.14)$ & $33.77(4.22)$ \\
\hline f (breaths/min) & $13.58(3.81)$ & $13.59(3.58)$ & $13.48(3.84)$ & $12.65(3.93)^{* * *}$ \\
\hline $\mathrm{P}_{\mathrm{I}}(\mathrm{mbar})$ & $1.17(0.36)$ & $1.19(0.99)$ & $2.32(0.83)$ & $8.91(3.80)^{* * *}$ \\
\hline $\mathrm{V}_{\mathrm{E}}(\mathrm{L} / \mathrm{min})$ & $10.04(2.75)$ & $9.52(2.38)$ & $12.47(3.11)$ & $11.24(3.11)^{* * *}$ \\
\hline $\mathrm{V}_{\mathrm{T}}(\mathrm{L})$ & $0.81(0.31)$ & $0.77(0.28)$ & $1.00(0.32)$ & $0.99(0.37)$ \\
\hline
\end{tabular}

Note. $\mathrm{PET}_{\mathrm{CO} 2}=$ end-tidal $\mathrm{CO}_{2}$ pressure; $\mathrm{f}=$ breathing frequency $; \mathrm{P}_{\mathrm{I}}=$ peak inspiratory mouth pressure; $\mathrm{T}_{\mathrm{I}}=$ inspiratory time; $\mathrm{V}_{\mathrm{E}}=$ minute ventilation; $\mathrm{V}_{\mathrm{T}}=$ tidal volume.

${ }^{\mathrm{a}} * p<.05$, *** $p<.001$ (Bonferroni-corrected) for the comparison of anticipation conditions (cue severe vs. cue mild) and perception conditions (severe dyspnea vs. mild dyspnea), respectively.

analysis yielded a significant correlation of brain activation with BCS scores. For the anticipation of dyspnea (contrast: cue severe vs. cue mild), the whole-brain analysis did not reveal significant activations. However, the corresponding ROI-based analysis yielded a significant positive correlation of BCS scores with anticipatory activation in the ACC $(x=4$, $y=36, z=-2$; ROI-corrected $p=.003$; see Figure 1). The offline correlation analyses of individual betas from ACC peak voxels and BCS scores $(r=.50, p<.001)$ remained significant when controlling for age $(r=.40, p<.001)$. Moreover, ACC activation was not correlated with parallel measures of the respiratory parameters $(r \mathrm{~s}<.09, p \mathrm{~s}>.50)$.

\section{4 | DISCUSSION}

The present study examined the associations between dyspnea catastrophizing and the anticipation and perception of

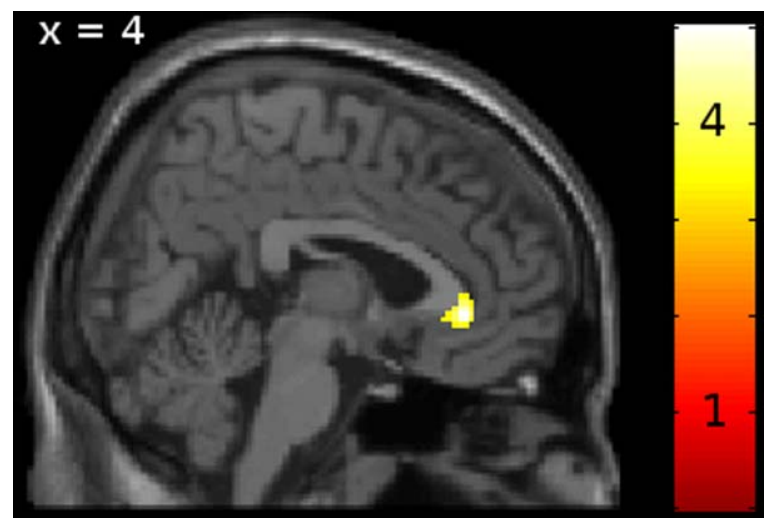

F I G URE 1 Dyspnea catastrophizing (BCS scores) is significantly correlated with increased brain activation during dyspnea anticipation in the ACC $(x=4, y=36, z=-2$; ROI-corrected $p=.003)$, after controlling for potential effects of trait anxiety (STAI-T). Results are displayed at a threshold of $p_{\text {uncorrected }}<.001$ and are superimposed on the T1-weighted standard template provided by SPM 8 resistive load-induced dyspnea. Explorative analyses showed no associations of dyspnea catastrophizing levels with baseline characteristics of the participants and their respiratory responses, except for a negative correlation with age. The main finding is a positive correlation between individual levels of dyspnea catastrophizing and activations of the ACC during the anticipation of resistive load-induced dyspnea, even after controlling for levels of general negative affectivity such as trait anxiety. Moreover, these activations were not related to respiratory parameters and remained significant when controlling for age.

The present results converge with several previous findings in pain research, where levels of pain catastrophizing were similarly associated with activations of the ACC (Cottam et al., 2016; Gracely et al., 2004; Seminowicz \& Davis, 2006). For example, Seminowicz and Davis (2006) found positive correlations between individual pain catastrophizing scores in healthy volunteers and pain-related activations during mild electrical median nerve stimulation within areas related to the emotional dimension of pain including the rostral ACC. Similarly, Gracely and colleagues (2004) observed increased ACC activation during pressure pain to be related to higher pain catastrophizing in fibromyalgia patients. Using arterial spin labeling (ASL), Cottam et al. (2016) demonstrated greater cerebral blood flow in the ACC to be correlated with subjective ratings of ongoing pain in patients with chronic osteoarthritis, which was related to pain catastrophizing scores.

However, we did not observe correlations of dyspnea catastrophizing with activations in further brain areas that have been reported in some of these studies, including the insula, amygdala, prefrontal cortex, or cerebellum (Cottam et al., 2016; Gracely et al., 2004; Mathur et al., 2016; Seminowicz $\&$ Davis, 2006). Furthermore, we did not find negative correlations between catastrophizing scores and brain activations, 
which were reported in two studies using pain stimuli and included the amygdala, prefrontal areas, and sensory cortices (Loggia et al., 2015; Seminowicz \& Davis, 2006). In addition, neither during the anticipation nor during the perception of dyspnea were significant correlations of dyspnea catastrophizing observed with activations in insula and amygdala, although these areas were activated in previous studies during anticipated and perceived dyspnea (Davenport \& Vovk, 2009; Evans, 2010; Faull et al., 2016; Herigstad et al., 2011), including the original study of Subsample 2 (Stoeckel et al., 2016). These discrepancies might be attributable to several differences between the present study and previous studies. These include differences in stimulus qualities (dyspnea vs. electrocutaneous pain vs. pressure pain), intensities (mild vs. severe), samples (healthy volunteers vs. pain patients), and/or imaging techniques (BOLD-fMRI vs. ASL). In addition, most previous studies in the field of pain research examined the perception of pain in relation to catastrophizing, which is not fully comparable to the anticipation of dyspnea. Two studies additionally examining the anticipation of pain reported contrasting results with one study finding negative, but not positive, correlations between catastrophizing and brain activations (Loggia et al., 2015), whereas the other study did not find any respective correlations (Burgmer et al., 2011). Finally, it might be speculated that the observed levels of dyspnea catastrophizing in the present study were too moderate, and only higher, clinically relevant levels would be related to the engagement of further (para)limbic brain areas such as insula and amygdala during the anticipation, but also perception of dyspnea.

The present observation of a positive correlation between dyspnea catastrophizing and ACC activity raises the question about the functional meaning of this association. The ACC has been shown to be involved in affective-motivational aspects of salient bodily stimuli including dyspnea and pain (Craig, 2002; Davenport \& Vovk, 2009; Herigstad et al., 2015; Tracey \& Mantyh, 2007; Vogt, 2014). For example, ACC activations have been shown to correlate with the perceived unpleasantness of dyspnea (Paulus et al., 2012) and pain (Grabenhorst, Rolls, \& Parris, 2008). Dyspnea catastrophizing thus might be related to an increased anticipatory processing of the expected affective unpleasantness of upcoming dyspnea. This is supported by the known role of the ACC for the processing of negative affectivity such as anxiety (Adolphs, 2013; Etkin \& Wager, 2007; Sehlmeyer et al., 2009). Moreover, the ACC is a crucial structure in the antinociceptive system, and both placebo-induced as well as opioid-induced pain reductions have been related to increased activation in this structure (Petrovic, Kalso, Petersson, \& Ingvar, 2002; Tracey \& Mantyh, 2007). Furthermore, the ACC plays an important role in affect regulation, for example, during (re)appraisal processes (Etkin et al., 2011).
Collectively, these findings suggest that dyspnea catastrophizing is related to increased top-down modulatory processing during the anticipation of dyspnea.

When interpreting the present results, some limitations need to be acknowledged. First, the retrospective nature of the present analyses requires confirmation in prospective study designs. Further, we investigated inspiratory resistive load-induced dyspnea evoking sensations of increased work and effort of breathing. Therefore, our findings cannot be generalized to other qualities of dyspnea such as chest tightness and air hunger. Moreover, our findings in healthy individuals cannot per se be generalized to patients suffering from chronic dyspnea. In addition, the average dyspnea catastrophizing levels were rather modest, with individual scores ranging between 0 and maximally 42 , which might not fully reflect dyspnea catastrophizing levels of dyspneic patients. For example, mean BCS scores of $18.1(S D=11.7)$ and $13.3(S D=11.5)$ were recently reported for patients with COPD at start and end, respectively, of a pulmonary rehabilitation program (Solomon et al., 2015). Therefore, future research is needed that also includes participants with higher levels of dyspnea catastrophizing, for example, from the upper tertile of BCS scores in population-based samples. This approach might also help to explain whether higher levels of dyspnea catastrophizing are associated with further activations in not only other (para)limbic areas such as insula and amygdala during anticipation, but also perception of dyspnea. Finally, it should be examined whether dyspnea catastrophizing is related to comparable brain activation patterns in patients with dyspnea, and how this is related to clinical outcomes. Respective findings would open new avenues to interventions aimed at reducing dyspnea catastrophizing in the treatment of chronic dyspnea.

\section{ACKNOWLEDGEMENTS}

This study was supported by grants from the German Research Foundation to A. v. L. (DFG LE 1843/9-2, 10-1 and 10-3). A. v. L. is supported by a research grant from the Research Fund KU Leuven, Belgium (STRT/13/002), by an infrastructure grant from the Herculesstichting, Belgium (AKUL/13/07), and by the "Asthenes" long-term structural funding Methusalem grant (\# METH/15/011) by the Flemish Government, Belgium. The authors wish to thank Timo Kraemer, Katrin Mueller, and Kathrin Wendt for technical assistance with data acquisition and all volunteers for participation in this study. The authors declare that there is no conflict of interest regarding the publication of this paper.

\section{REFERENCES}

Adolphs, R. (2013). The biology of fear. Current Biology, 23(2), R79-R93. https://doi.org/10.1016/j.cub.2012.11.055 
Alius, M. G., Pané-Farré, C. A., Von Leupoldt, A., \& Hamm, A. O. (2013). Induction of dyspnea evokes increased anxiety and maladaptive breathing in individuals with high anxiety sensitivity and suffocation fear. Psychophysiology, 50(5), 488-497. https://doi. org/10.1111/psyp.12028

American Thoracic Society. (1999). Dyspnea. mechanisms, assessment, and management: A consensus statement. American Journal of Respiratory and Critical Care Medicine, 159(1), 321-340.

Beckmann, C. F., \& Smith, S. M. (2004). Probabilistic independent component analysis for functional magnetic resonance imaging. IEEE Transactions on Medical Imaging, 23(2), 137-152. https:// doi.org/10.1109/TMI.2003.822821

Borg, G. A. (1982). Psychophysical bases of perceived exertion. Medicine and Science in Sports and Exercise, 14(5), 377-381.

Brooks, J. C., Faull, O. K., Pattinson, K. T., \& Jenkinson, M. (2013). Physiological noise in brainstem fMRI. Frontiers in Human Neuroscience, 7, 623, https://doi.org/10.3389/fnhum.2013.00623

Burgmer, M., Petzke, F., Giesecke, T., Gaubitz, M., Heuft, G., \& Pfleiderer, B. (2011). Cerebral activation and catastrophizing during pain anticipation in patients with fibromyalgia. Psychosomatic Medicine, 73(9), 751-759. https://doi.org/10.1097/PSY.0b013e318236588a

Chan, P.-Y. S., Cheng, C.-H., Hsu, S.-C., Liu, C.-Y., Davenport, P. W., \& von Leupoldt, A. (2015). Respiratory sensory gating measured by respiratory-related evoked potentials in generalized anxiety disorder. Frontiers in Psychology, 6, 957. https://doi.org/10. 3389/fpsyg.2015.00957

Chan, P.-Y. S., von Leupoldt, A., Bradley, M. M., Lang, P. J., \& Davenport, P. W. (2012). The effect of anxiety on respiratory sensory gating measured by respiratory-related evoked potentials. Biological Psychology, 91(2), 185-189. https://doi.org/10.1016/j. biopsycho.2012.07.001

Chan, P.-Y. S., von Leupoldt, A., Liu, C.-Y., \& Hsu, S.-C. (2014). Respiratory perception measured by cortical neural activations in individuals with generalized anxiety disorder. Respiratory Physiology \& Neurobiology, 204, 36-40. https://doi.org/10.1016/j.resp. 2014.09.009

Chenivesse, C., Chan, P.-Y., Tsai, H.-W., Wheeler-Hegland, K., Silverman, E., von Leupoldt, A., ... Davenport, P. (2014). Negative emotional stimulation decreases respiratory sensory gating in healthy humans. Respiratory Physiology \& Neurobiology, 204, 50-57. https://doi.org/10.1016/j.resp.2014.08.019

Cottam, W. J., Condon, L., Alshuft, H., Reckziegel, D., \& Auer, D. P. (2016). Associations of limbic-affective brain activity and severity of ongoing chronic arthritis pain are explained by trait anxiety. NeuroImage. Clinical, 12, 269-276. https://doi.org/10.1016/j.nicl.2016.06.022

Craig, A. D. (2002). How do you feel? Interoception: The sense of the physiological condition of the body. Nature Reviews. Neuroscience, 3(8), 655-666. https://doi.org/10.1038/nrn894

Davenport, P. W., \& Vovk, A. (2009). Cortical and subcortical central neural pathways in respiratory sensations. Respiratory Physiology \& Neurobiology, 167(1), 72-86. https://doi.org/10.1016/j. resp.2008.10.001

Desmond, J. E., \& Glover, G. H. (2002). Estimating sample size in functional MRI (fMRI) neuroimaging studies: Statistical power analyses. Journal of Neuroscientific Methods, 118(2), 115-128. https://doi.org/10.1016/S0165-0270(02)00121-8
Esser, R. W., Stoeckel, M. C., Kirsten, A., Watz, H., Taube, K., Lehmann, K., ... von Leupoldt, A. (2017). Brain activation during perception and anticipation of dyspnea in chronic obstructive pulmonary disease. Frontiers in Physiology, 8, 617. https://doi.10. 3389/fphys.2017.00617

Etkin, A., Egner, T., \& Kalisch, R. (2011). Emotional processing in anterior cingulate and medial prefrontal cortex. Trends in Cognitive Sciences, 15(2), 85-93. https://doi.org/10.1016/j.tics.2010.11. 004

Etkin, A., \& Wager, T. D. (2007). Functional neuroimaging of anxiety: A meta-analysis of emotional processing in PTSD, social anxiety disorder, and specific phobia. American Journal of Psychiatry, 164(10), 1476-1488. https://doi.org/10.1176/appi.ajp. 2007.07030504

Evans, K. C. (2010). Cortico-limbic circuitry and the airways: Insights from functional neuroimaging of respiratory afferents and efferents. Biological Psychology, 84(1), 13-25. https://doi.org/10. 1016/j.biopsycho.2010.02.005

Faull, O. K., Jenkinson, M., Ezra, M., \& Pattinson, K. T. (2016). Conditioned respiratory threat in the subdivisions of the human periaqueductal gray. eLife, 5, e12047. https://doi.org/10.7554/ eLife. 12047

Fischer, M. J., Scharloo, M., Abbink, J., van 't Hul, A., van Ranst, D., Rudolphus, A., ... Kaptein, A. A. (2012). Concerns about exercise are related to walk test results in pulmonary rehabilitation for patients with COPD. International Journal of Behavioral Medicine, 19(1), 39-47. https://doi.org/10.1007/s12529-010-91309

Grabenhorst, F., Rolls, E. T., \& Parris, B. A. (2008). From affective value to decision-making in the prefrontal cortex. European Journal of Neuroscience, 28(9), 1930-1939. https://doi.org/10.1111/j. 1460-9568.2008.06489.x

Gracely, R. H., Geisser, M. E., Giesecke, T., Grant, M. A. B., Petzke, F., Williams, D. A., \& Clauw, D. J. (2004). Pain catastrophizing and neural responses to pain among persons with fibromyalgia. Brain, 127(Pt 4), 835-843. https://doi.org/10.1093/brain/awh098

Grupe, D. W., \& Nitschke, J. B. (2013). Uncertainty and anticipation in anxiety: An integrated neurobiological and psychological perspective. Nature Reviews. Neuroscience, 14(7), 488-501. https:// doi.org/10.1038/nrn3524

Hayen, A., Herigstad, M., \& Pattinson, K. T. S. (2013). Understanding dyspnea as a complex individual experience. Maturitas, 76(1), 45-50. https://doi.org/10.1016/j.maturitas.2013.06.005

Herigstad, M., Hayen, A., Evans, E., Hardinge, F. M., Davies, R. J., Wiech, K., \& Pattinson, K. T. S. (2015). Dyspnea-related cues engage the prefrontal cortex: Evidence from functional brain imaging in COPD. Chest, 148(4), 953-961. https://doi.org/10. 1378/chest.15-0416

Herigstad, M., Hayen, A., Wiech, K., \& Pattinson, K. T. S. (2011). Dyspnoea and the brain. Respiratory Medicine, 105(6), 809-817. https://doi.org/10.1016/j.rmed.2010.12.022

Holroyd, K. A., Drew, J. B., Cottrell, C. K., Romanek, K. M., \& Heh, V. (2007). Impaired functioning and quality of life in severe migraine: The role of catastrophizing and associated symptoms. Cephalalgia, 27(10), 1156-1165. https://doi.org/10.1111/j.14682982.2007.01420.x 
Holtz, K., Pané-Farré, C. A., Wendt, J., Lotze, M., \& Hamm, A. O. (2012). Brain activation during anticipation of interoceptive threat. NeuroImage, 61(4), 857-865. https://doi.org/10.1016/j.neuroimage.2012.03.019

Janson, C., Björnsson, E., Hetta, J., \& Boman, G. (1994). Anxiety and depression in relation to respiratory symptoms and asthma. American Journal of Respiratory and Critical Care Medicine, 149(4 Pt 1), 930-934.

Janssens, T., De Peuter, S., Stans, L., Verleden, G., Troosters, T., Decramer, M., \& Van den Bergh, O. (2011). Dyspnea perception in COPD: Association between anxiety, dyspnea-related fear, and dyspnea in a pulmonary rehabilitation program. Chest, 140(3), 618-625. https://doi.org/10.1378/chest.10-3257

Janssens, T., Verleden, G., De Peuter, S., Van Diest, I., \& Van den Bergh, O. (2009). Inaccurate perception of asthma symptoms: A cognitive-affective framework and implications for asthma treatment. Clinical Psychology Review, 29(4), 317-327. https://doi. org/10.1016/j.cpr.2009.02.006

Keil, D. C., Stenzel, N. M., Kühl, K., Vaske, I., Mewes, R., Rief, W., \& Kenn, K. (2014). The impact of chronic obstructive pulmonary disease-related fears on disease-specific disability. Chronic Respiratory Disease, 11(1), 31-40. https://doi.org/10.1177/ 1479972313516881

Kelly, R. E., Alexopoulos, G. S., Wang, Z., Gunning, F. M., Murphy, C. F., Morimoto, S. S., . . Hoptman, M. J. (2010). Visual inspection of independent components: Defining a procedure for artifact removal from fMRI data. Journal of Neuroscience Methods, 189 (2), 233-245. https://doi.org/10.1016/j.jneumeth.2010.03.028

Kühl, K., Kuhn, C., Kenn, K., \& Rief, W. (2011). [The COPDAnxiety-Questionnaire (CAF): A new instrument to assess illness specific anxiety in COPD patients]. Psychotherapie, Psychosomatik, Medizinische Psychologie, 61(1), e1-9. https://doi.org/10. 1055/s-0030-1248281

Laviolette, L., Laveneziana, P., \& ERS Research Seminar Faculty. (2014). Dyspnoea: A multidimensional and multidisciplinary approach. European Respiratory Journal, 43(6), 1750-1762. https://doi.org/10.1183/09031936.00092613

Leeuw, M., Goossens, M. E. J. B., Linton, S. J., Crombez, G., Boersma, K., \& Vlaeyen, J. W. S. (2007). The fear-avoidance model of musculoskeletal pain: Current state of scientific evidence. Journal of Behavioral Medicine, 30(1), 77-94. https://doi. org/10.1007/s10865-006-9085-0

Livermore, N., Butler, J. E., Sharpe, L., McBain, R. A., Gandevia, S. C., \& McKenzie, D. K. (2008). Panic attacks and perception of inspiratory resistive loads in chronic obstructive pulmonary disease. American Journal of Respiratory and Critical Care Medicine, 178(1), 7-12. https://doi.org/10.1164/rccm.200711-1700OC

Livermore, N., Dimitri, A., Sharpe, L., McKenzie, D. K., Gandevia, S. C., \& Butler, J. E. (2015). Cognitive behaviour therapy reduces dyspnoea ratings in patients with chronic obstructive pulmonary disease (COPD). Respiratory Physiology \& Neurobiology, 216, 35-42. https://doi.org/10.1016/j.resp.2015.05.013

Livermore, N., Sharpe, L., \& McKenzie, D. (2012). Catastrophic interpretations and anxiety sensitivity as predictors of panicspectrum psychopathology in chronic obstructive pulmonary disease. Journal of Psychosomatic Research, 72(5), 388-392. https:// doi.org/10.1016/j.jpsychores.2012.02.001
Loggia, M. L., Berna, C., Kim, J., Cahalan, C. M., Martel, M.-O., Gollub, R. L., ... Edwards, R. R. (2015). The lateral prefrontal cortex mediates the hyperalgesic effects of negative cognitions in chronic pain patients. Journal of Pain, 16(8), 692-699. https:// doi.org/10.1016/j.jpain.2015.04.003

Mahler, D. A., \& O’Donnell, D. E. (2015). Recent advances in dyspnea. Chest, 147(1), 232-241. https://doi.org/10.1378/chest.140800

Mathur, V. A., Moayedi, M., Keaser, M. L., Khan, S. A., Hubbard, C. S., Goyal, M., \& Seminowicz, D. A. (2016). High frequency migraine is associated with lower acute pain sensitivity and abnormal insula activity related to migraine pain intensity, attack frequency, and pain catastrophizing. Frontiers in Human Neuroscience, 10, 489. https://doi.org/10.3389/fnhum.2016.00489

Miller, M. R., Hankinson, J., Brusasco, V., Burgos, F., Casaburi, R., Coates, A., ... ATS/ERS Task Force. (2005). Standardisation of spirometry. European Respiratory Journal, 26(2), 319-338. https://doi.org/10.1183/09031936.05.00034805

Pappens, M., Smets, E., Van Den Bergh, O., \& Van Diest, I. (2012). Fear of suffocation alters respiration during obstructed breathing. Psychophysiology, 49(6), 829-832. https://doi.org/10.1111/j.14698986.2012.01355.x

Parshall, M. B., Schwartzstein, R. M., Adams, L., Banzett, R. B., Manning, H. L., Bourbeau, J., ... American Thoracic Society Committee on Dyspnea. (2012). An official American Thoracic Society statement: Update on the mechanisms, assessment, and management of dyspnea. American Journal of Respiratory and Critical Care Medicine, 185(4), 435-452. https://doi.org/10.1164/ rccm.201111-2042ST

Paulus, M. P. (2013). The breathing conundrum-interoceptive sensitivity and anxiety. Depression and Anxiety, 30(4), 315-320. https://doi.org/10.1002/da.22076

Paulus, M. P., Flagan, T., Simmons, A. N., Gillis, K., Kotturi, S., Thom, N., .. Swain, J. L. (2012). Subjecting elite athletes to inspiratory breathing load reveals behavioral and neural signatures of optimal performers in extreme environments. PLOS ONE, 7(1), e29394. https://doi.org/10.1371/journal.pone.0029394

Petrovic, P., Kalso, E., Petersson, K. M., \& Ingvar, M. (2002). Placebo and opioid analgesia-Imaging a shared neuronal network. Science, 295(5560), 1737-1740. https://doi.org/10.1126/science. 1067176

Scano, G., Gigliotti, F., Stendardi, L., \& Gagliardi, E. (2013). Dyspnea and emotional states in health and disease. Respiratory Medicine, 107(5), 649-655. https://doi.org/10.1016/j.rmed.2012. 12.018

Sehlmeyer, C., Schöning, S., Zwitserlood, P., Pfleiderer, B., Kircher, T., Arolt, V., \& Konrad, C. (2009). Human fear conditioning and extinction in neuroimaging: A systematic review. PLOS ONE, 4 (6), e5865. https://doi.org/10.1371/journal.pone.0005865

Seminowicz, D. A., \& Davis, K. D. (2006). Cortical responses to pain in healthy individuals depends on pain catastrophizing. Pain, 120(3), 297-306. https://doi.org/10.1016/j.pain.2005.11.008

Severeijns, R., Vlaeyen, J. W., van den Hout, M. A., \& Weber, W. E. (2001). Pain catastrophizing predicts pain intensity, disability, and psychological distress independent of the level of physical impairment. Clinical Journal of Pain, 17(2), 165-172. 
Solomon, B. K., Wilson, K. G., Henderson, P. R., Poulin, P. A., Kowal, J., \& McKim, D. A. (2015). A breathlessness catastrophizing scale for chronic obstructive pulmonary disease. Journal of Psychosomatic Research, 79(1), 62-68. https://doi.org/10.1016/j. jpsychores.2014.11.020

Spielberger, C. D., Gorsuch, R. L., \& Lushene, R. E. (1970). Manual for the State-Trait Anxiety Inventory. Palo Alto, CA: Consulting Psychologists Press.

Spinhoven, P., van Peski-Oosterbaan, A. S., Van der Does, A. J., Willems, L. N., \& Sterk, P. J. (1997). Association of anxiety with perception of histamine induced bronchoconstriction in patients with asthma. Thorax, 52(2), 149-152.

Stoeckel, M. C., Esser, R. W., Gamer, M., Büchel, C., \& von Leupoldt, A. (2015). Brain mechanisms of short-term habituation and sensitization toward dyspnea. Frontiers in Psychology, 6, 748. https://doi.org/10.3389/fpsyg.2015.00748

Stoeckel, M. C., Esser, R. W., Gamer, M., Büchel, C., \& von Leupoldt, A. (2016). Brain responses during the anticipation of dyspnea. Neural Plasticity, 2016, 6434987. https://doi.org/10.1155/ 2016/6434987

Stoeckel, M. C., Esser, R. W., Gamer, M., Kalisch, R., Büchel, C., \& von Leupoldt, A. (2015). Amygdala response to anticipation of dyspnea is modulated by 5-HTTLPR genotype. Psychophysiology, 52(7), 973-976. https://doi.org/10.1111/psyp.12417

Sullivan, M. J., Bishop, S. R., \& Pivik, J. (1995). The Pain Catastrophizing Scale: Development and validation. Psychological Assessment, 7(4), 524-532. https://doi.org/10.1037/1040-3590.7.4. 524

Sullivan, M. J. L., Lynch, M. E., \& Clark, A. J. (2005). Dimensions of catastrophic thinking associated with pain experience and disability in patients with neuropathic pain conditions. Pain, 113(3), 310-315. https://doi.org/10.1016/j.pain.2004.11.003

Sullivan, M. J., Thorn, B., Haythornthwaite, J. A., Keefe, F., Martin, M., Bradley, L. A., \& Lefebvre, J. C. (2001). Theoretical perspectives on the relation between catastrophizing and pain. Clinical Journal of Pain, 17(1), 52-64.

Sutton, K., Cooper, M., Pimm, J., \& Wallace, L. (1999). Anxiety in chronic obstructive pulmonary disease: The role of illness specific catastrophic thoughts. Cognitive Therapy and Research, 23(6), 573-585. https://doi.org/10.1023/A:1018780623406

Tracey, I., \& Mantyh, P. W. (2007). The cerebral signature for pain perception and its modulation. Neuron, 55(3), 377-391. https:// doi.org/10.1016/j.neuron.2007.07.012

Tzourio-Mazoyer, N., Landeau, B., Papathanassiou, D., Crivello, F., Etard, O., Delcroix, N., .. Joliot, M. (2002). Automated anatomical labeling of activations in SPM using a macroscopic anatomical parcellation of the MNI MRI single-subject brain. NeuroImage, 15(1), 273-289. https://doi.org/10.1006/nimg.2001.0978

Van Oudenhove, L., \& Aziz, Q. (2013). The role of psychosocial factors and psychiatric disorders in functional dyspepsia. Nature Reviews. Gastroenterology \& Hepatology, 10(3), 158-167. https://doi.org/10.1038/nrgastro.2013.10
Vogt, B. A. (2014). Submodalities of emotion in the context of cingulate subregions. Cortex, 59, 197-202. https://doi.org/10.1016/j. cortex.2014.04.002

von Leupoldt, A., Balewski, S., Petersen, S., Taube, K., SchubertHeukeshoven, S., Magnussen, H., \& Dahme, B. (2007). Verbal descriptors of dyspnea in patients with COPD at different intensity levels of dyspnea. Chest, 132(1), 141-147. https://doi.org/10. 1378/chest.07-0103

von Leupoldt, A., Chan, P.-Y. S., Esser, R. W., \& Davenport, P. W. (2013). Emotions and neural processing of respiratory sensations investigated with respiratory-related evoked potentials. Psychosomatic Medicine, 75(3), 244-252. https://doi.org/10.1097/PSY. 0b013e31828251cf

von Leupoldt, A., \& Dahme, B. (2005). Cortical substrates for the perception of dyspnea. Chest, 128(1), 345-354. https://doi.org/10. 1378/chest.128.1.345

von Leupoldt, A., \& Janssens, T. (2016). Could targeting disease specific fear and anxiety improve COPD outcomes? Expert Review of Respiratory Medicine, 10(8), 835-837. https://doi.org/10.1080/ 17476348.2016.1198697

von Leupoldt, A., Sommer, T., Kegat, S., Baumann, H. J., Klose, H., Dahme, B., \& Büchel, C. (2008). The unpleasantness of perceived dyspnea is processed in the anterior insula and amygdala. American Journal of Respiratory and Critical Care Medicine, 177(9), 1026-1032. https://doi.org/10.1164/rccm.200712-1821OC

von Leupoldt, A., Sommer, T., Kegat, S., Baumann, H. J., Klose, H., Dahme, B., \& Büchel, C. (2009). Dyspnea and pain share emotion-related brain network. NeuroImage, 48(1), 200-206. https://doi.org/10.1016/j.neuroimage.2009.06.015

von Leupoldt, A., Taube, K., Lehmann, K., Fritzsche, A., \& Magnussen, H. (2011). The impact of anxiety and depression on outcomes of pulmonary rehabilitation in patients with COPD. Chest, 140(3), 730736. https://doi.org/10.1378/chest.10-2917

von Leupoldt, A., van den Bergh, O., \& Davenport, P. W. (2014). Anxiety, depression and panic. In D. A. Mahler \& D. E. O'Donnell (Eds.), Dyspnea: Mechanisms, measurement and management (3rd ed., pp. 129-143). Boca Raton, FL: CRC Press.

Xu, W., Collet, J.-P., Shapiro, S., Lin, Y., Yang, T., Platt, R. W., ... Bourbeau, J. (2008). Independent effect of depression and anxiety on chronic obstructive pulmonary disease exacerbations and hospitalizations. American Journal of Respiratory and Critical Care Medicine, 178(9), 913-920. https://doi.org/10.1164/rccm.200804$6190 \mathrm{C}$

How to cite this article: Cornelia Stoeckel M, Esser RW, Gamer M, Büchel C, von Leupoldt A. Dyspnea catastrophizing and neural activations during the anticipation and perception of dyspnea. Psychophysiology. 2017;00:1-10. https://doi.org/10.1111/psyp.13004 